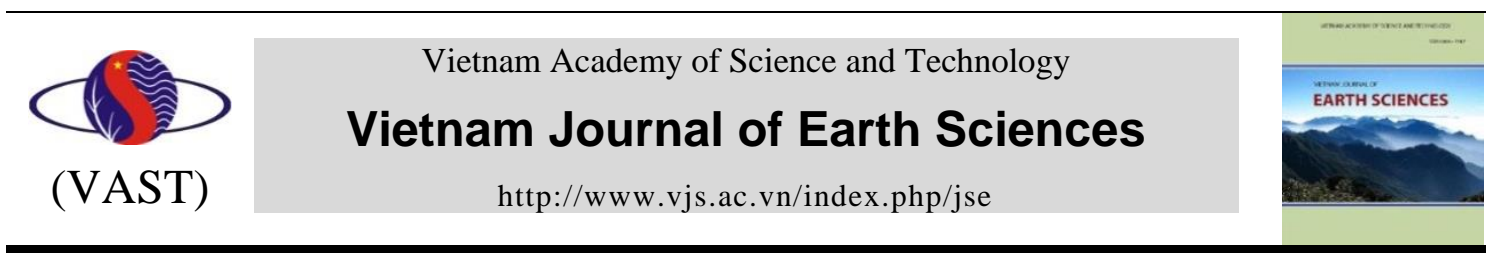

\title{
Seismic Status in Bangladesh
}

\author{
Syed Mustafizur Rahman ${ }^{*}$, Md. Habibur Rahman², Md. Omar Faruk3, and Md. Sultan-Ul-Islam4 \\ ${ }^{I}$ Department of Applied Physics and Electronic Engineering, University of Rajshahi, Rajshahi 6205, \\ Bangladesh \\ ${ }^{2}$ CEGIS, Dhaka 1212, Bangladesh \\ ${ }^{3}$ Department of ICE, Pabna University of Science and Technology, Pabna 6600, Bangladesh \\ ${ }^{4}$ Institute of Environmental Science, University of Rajshahi, Rajshahi 6205, Bangladesh
}

Received 12 February 2018; Received in revised form 01 April 2018; Accepted 5 April 2018

\begin{abstract}
Seismic status in Bangladesh has been investigated using earthquake data recorded by the global network of USGS during 1980 to 2016. Seismicity parameters such as magnitude of completeness $M_{c}, b$-value and a-value are being estimated. It has observed that the overall $b$-value in and around Bangladesh is of 0.84 , which is seemed to be seismically active zone. As, reliable $b$-value assessment can lead to better seismic hazard analysis, reliable magnitude of completeness $M_{c}$ can lead to $b$-value assessment of an area, this work has dealt and estimated magnitude of completeness $M_{c}$ using various techniques for the whole region for a reliable estimation. Estimated $M_{c}$ is obtained to be around 3.9-4.7, which lead to $b$-value of 0.93. Spatial variations of $M_{c}$ and $b$-value have been investigated for $1^{\circ} \times 1^{\circ}$ horizontal and vertical rectangular regions for the study area between $18-29^{\circ} \mathrm{N}$ and $84-95^{\circ} \mathrm{E}$. Estimated $M_{c}$ and $b$ value along with $a$-value are then averaged for the common regions in the pair of horizontal and vertical regions. Results are then being presented in the form of maps. The findings resemble as, the $M_{c}$ is low at the border line of N-W Bangladesh, and a line from Cox's Bazaar to Sylhet through Hill tracts. Remain parts belong to the $M_{c}$ value of 4.14.2 , thus the $b$-value obtained is varying from 0.68 to 1.2 , where, the value is higher at region in Chittagong and Barisal division that extends toward north through part of Dhaka to Sylhet and lower at Rajshahi, Rangpur and part of Khulna division, while $a$-value is varying from 5.0 to 7.2 mostly from west to east.
\end{abstract}

Keywords: earthquake; seismicity; magnitude; completeness.

(C)2018 Vietnam Academy of Science and Technology

\section{Introduction}

Earthquake is one of the most natural devastating events that can hurl people around and destroy lives and properties. The study of earthquake distribution in space and time in a region is known as seismicity. Seismic activities are being referred to frequency and magnitude of earthquakes experienced over a period of time. Realistic assessment of seismic activities in Bangladesh may assist to reduce

*Corresponding author, Email: smrahman@ru.ac.bd the risk from this catastrophic disaster. Earthquake catalogues in this regard are the only sources as the most important products for studying seismological activities those can support to understand earthquake physics and let to learn seismotectonics, seismicity or seismic hazard of an area. Even in modern time it is still difficult to obtain most reliable catalogues. Earthquake catalogue is basically the result of recorded signals of seismometers and processed by a variety of techniques and assumptions (Zuniga and Wiemer, 1999), hence adequate care should have been taken 
Syed Mustafizur Rahman, et al./Vietnam Journal of Earth Sciences 40 (2018)

to assess the quality, consistency or homogeneity before using it to scientific analyses (Hafiez, 2015). In order to avoid such complexities, the present analysis intends to work with one catalog for better uniformity.

The frequency-magnitude distribution (FMD) of earthquakes introduced by Gutenberg and Richter (1944) known as G-R law is the basis as well as the basic relation for any seismicity studies. In order to understand meaningful interpretation of frequencymagnitude distribution in an earthquake cata$\log$, the magnitude of completeness, $M_{c}$ is defined as the minimum magnitude above which all earthquakes within a certain region are reliably recorded (Naylor, et al., 2010). The G$\mathrm{R}$ law is written as below.

$$
\log _{10} N(M)=a-b M
$$

where, $M$ is the magnitude, $N(M)$ is the number of earthquakes occurred in a specific time with magnitudes $M \geq M_{c}, a$ is the earthquake productivity, and $b$ describes the relative distribution of small and large earthquakes. The $b$-value in the Gutenberg-Richter power law is an indicator which describes seismic status of an area. However, there are difficulties to determine reliable $b$-value (Felzer, 2006), particularly setting magnitude of completeness $M_{c}$ which can lead to improper $b$-value estimation unless $M_{c}$ is determined properly. This research work intends to estimate $b$-value and magnitude of completeness $M_{c}$ in Bangladesh using the earthquake catalogs retrieved from USGS (USGS, 2012). Few initiatives were being taken in the past to define seismic hazard map, earthquake cata$\log$, national building code, peak ground acceleration and seismicity analysis in Bangladesh (GSB, 2018; Siddique, 2015; AlHussaini, 2006). However, the works are yet to seem as much more meaningful inputs. In order to estimate meaningful seismicity in Bangladesh a location map and epicenters of occurred earthquakes over the years in the study area are shown in Figure 1.

In addition, there are several plausible explanations in the observation of variations in $b$-values according to tectonic or geologic setting of an area. Therefore, a description of the geological overview of the study area has incorporated in the following section.

\section{Geological Setting of Bangladesh}

Bangladesh belongs to South Asia and lies between $20^{\circ} 34^{\prime}-26^{\circ} 38^{\prime} \mathrm{N}$ and $88^{\circ} 01^{\prime}$ $92^{\circ} 41^{\prime} \mathrm{E}$. The area of the country is approximately $147,570 \mathrm{~km}^{2}$ with more than $710 \mathrm{~km}$ long coastlines. It covers about $80 \%$ of the Bengal Basin. The land area is following a downward slope of $1-2^{\circ}$ from north-west to south-east direction. Tectonic framework of the region is shown in Figure 2 that entails the existence of plate boundaries, shelf, fault, trough, threshold, long hinge zone and the complicated river basin system.

Physiographically, the study area is divided into: Territory Hilly regions (east and north-eastern frontier), Pleistocene Terraces (N-W and central part), Tippera surface, Tista Fan (north eastern part), Floodplains and Deltaic plain of the Ganges-Brahmaputra-Meghna delta complex, Sylhet Depression and Inland marshes (scattered all over Bangladesh) etc. (Rashid, 1991; Reimann, 1993). Holocene unconsolidated sediments (sands, silts, clays, gravels and peats) from a few hundred to thousands of meters cover the Floodplains and the Delta. The whole basin area is crisscrossed by several basement controlled fault configuring the present structural and geomorphic setup of the country (Hunting, 1981). The Bengal Basins are bounded in the north by the Dauki fault and Bangladesh-Burma subduction zone in the east. Beside these several faults like hinge zone, Bogra fault, Ganges and Jamuna lineaments, Korotoya fault are prominent structures can trigger the earthquakes in the region.

\section{Data and Methods}

This work has used the source parameters of earthquake data of the study area for the duration from 1990-2016 recorded by USGS using global seismic network. Under Earthquake Hazards Program, USGS has been rec- 
Vietnam Journal of Earth Sciences, 40(2), 178-192

orded the millions of earthquakes in the liable source in the world. Earthquake data are world. It is believed that the ANSS Compre- downloaded from USGS for the present rehensive Earthquake Catalog (ComCat) is a re- search as shown in Figure 1.



Figure 1. Study area and the map of earthquake epicenters during 1990-2016, retrieved from USGS 


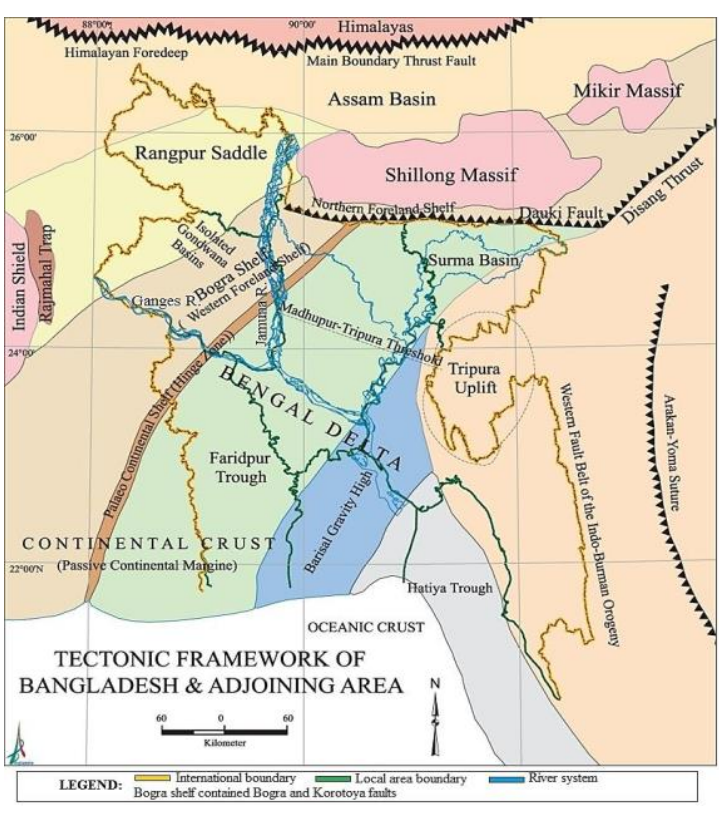

Figure 2. Tectonic framework of Bangladesh (after Banglapedia, 2012)

\subsection{Magnitude of Completeness}

Magnitude of completeness $M_{c}$ is the minimum magnitude at where most of the earthquakes preferably $100 \%$ in a space-time volume are detected. Assessment of a correct magnitude of completeness $M_{c}$ is crucial since too high value of $M_{c}$ can lead to undersampling by discarding usable data, while too low value can lead to erroneous or biased seismicity parameters by using incomplete data (Mignan and Woessner, 2012).

A number of contributions have provided various techniques to compute $M_{c}$ upon validity of the G-R law (Wyss et al., 1999; Wiemer and Wyss, 2000; Cao and Gao, 2002; Woessner and Wiemer, 2005; Amorese, 2007). Computation of $M_{c}$ is straightforward and based on readily accessible parametric catalog data. The most basic way is to estimate $M_{c}$ by fitting a G-R model to the observed frequency-magnitude distribution. The magnitude at where the FMD departs from the G-R law is taken as an estimate of $M_{c}$ (Zuniga and Wyss, 1995). In few cases a visual evaluation could lead to a correct estimate of completeness magnitude. On the contrary, it has been seemed difficulties in visual estimation of completeness (Naylor et al., 2010). Spatiotemporal heterogeneities can cause to change in $M_{c}$, which is being observed in frequency magnitude distributions (Wiemer and Wyss, 2000 and Mignan et al., 2011). There are both opinions that FMD has been observed as to be scaled as approximately magnitude 0 event or the events which can be only detected within $10 \mathrm{~m}$ form the source (Abercrombie and Brune, 1994), on the other hand, few contributors have suggested changes in scaling at higher or smaller magnitude events (e.g., Lomnitz-Adler and Lomnitz, 1979; Utsu, 1999 and Aki, 1987). However, the changes in slope of G-R model are not seemed to be relevant for the estimate of $M_{c}$. It is believed that dominant factor changing the slope of G-R model is incompleteness in reporting for smaller magnitudes (Wiemer \& Wyss, 2000). The work to be done here is slightly different as small and/or very small $(<3.0 \mathrm{M})$ events are not available from the catalogues to be used but magnitude completeness $M_{c}$ and $b$-value are to be learned for the study area. In this context the popular techniques to estimate $M_{c}$ are being employed to observe the $M_{c}$ in the present analysis. The techniques based on validity of G-R law are being explained below.

\subsubsection{Maximum Curvature Technique (MAXC)}

The Maximum Curvature (MAXC) technique (Mignan and Woessner, 2012, Wyss et al., 1999 and Wiemer and Wyss, 2000) is non parametric technique but fast and straightforward way to estimate $M_{c}$ and consists in defining the point of the maximum curvature by computing the maximum value of the first derivative of the frequency-magnitude curve (FMD).

$$
M_{c}=m \quad \text { while, } \frac{\partial(N(m)}{\partial m}=\max
$$

In practice, this matches the magnitude bin with the highest frequency of events in the non-cumulative FMD. Despite the easy applicability of this approach $M_{c}$ can be underestimated in the case of gradually curved FMDs. 


\subsubsection{Goodness-of-Fit Test (GFT)}

The Goodness-of-fit test (GFT) proposed by Wiemer and Wyss (2000), calculates $M_{c}$ by comparing the observed FMD with synthetic ones. The goodness-of-fit is evaluated by the parameter $R$, absolute difference of the number of events in each magnitude bin between the observed and synthetic G-R distributions. Synthetic distributions are calculated using estimated $a$-value and $b$-value of the observed dataset for $M \geq M_{c o}$ as a function of ascending cutoff magnitude $M_{c o}$.

$R\left(a, b, M_{c o}\right)=100-\left(\frac{\sum_{M_{c o}}^{M_{\max }}\left|B_{i}-S_{i}\right|}{\sum_{i} B_{i}} 100\right)$

where, $B_{i}$ and $S_{i}$ are the observed and predicted cumulative number of events in each magnitude bin. $M_{c}$ is found at the first magnitude cutoff at which the observed data for $M \geq$ $M_{c o}$ is modeled by a straight line for a fixed confidence level, e.g. $R=90 \%$ or $95 \%$.

\subsection{3. $M_{c}$ by $b$-value stability $(M B S)$}

Cao and Gao (2002) estimated $M_{c}$ using the stability of the $b$-value as a function of cutoff magnitude $M_{c o}$, referred to as MBS by Woessner and Wiemer (2005). This model is based on the assumption that $b$-value estimates ascend for $M_{c o}<M_{c}$ and remain constant for $M \geq M_{c o}$. If $M_{c o}<M_{c}$, the resulting $b$-value is incorrect. As $M_{c o}$ approaches $M_{c}$, the $b$-value approaches its true value and remains constant for $M_{c o}>M_{c}$.

$M_{c}$ is defined as the magnitude for which the change in $b$-value $\Delta b$ between two successive magnitude bins is smaller than 0.03 . Woessner and Wiemer (2005) have shown that this principle is unstable since the frequency of events in single magnitude bins can vary strongly. In order to satisfy such objective measure and to stabilize numerically, Woessner and Wiemer (2005) have used the $b$-value uncertainty $\partial b$ according to Shi and Bolt (1982) as:

$$
\partial b=2.3 b^{2} \sqrt{\frac{\sum_{i=1}^{N}\left(M_{i}-\langle M\rangle\right)^{2}}{N(N-1)}}
$$

with $\langle M\rangle$ being the mean magnitude and $N$ the number of events. $M_{c}$ is then defined as the first magnitude increment at which

$$
\Delta b=\left|b_{\text {ave }}-b\right| \leq \partial b
$$

The arithmetic mean $b_{\text {ave }}$ is calculated from $b$-values of successive cutoff magnitudes $M_{c}$ in half a magnitude range $d M=0.5$ such as

$$
b_{\text {ave }}=\sum_{M_{c o}}^{M_{c o}+d M} b\left(M_{c o}\right) \Delta m / d M
$$

for a bin size $\Delta m=0.1$. Large magnitude ranges are preferable, and would be justified for FMDs that perfectly obey a power-law.

\subsection{4. $M_{c}$ from the Entire Magnitude Range (EMR)}

Entire magnitude range (EMR) method includes the events below $M_{c}$. This method consisting of two parts: the G-R law for the complete part and the cumulative normal distribution for the incomplete part of the noncumulative FMD. The model attempts to reproduce the entire frequency-magnitude distribution, thus fits the incompletely observed part.

The EMR approach is explained as the non-cumulative FMD can be described by the intensity $\lambda$ (normalized number of events) at magnitude $m$ as

$$
\lambda(m)=\lambda_{o}(m) q(m)
$$

with

$$
\lambda_{o}(m \mid \beta)=e^{-\beta m}
$$

where, $\beta=b \log 10$ and $q(m)$ is a detection function with $0 \leq q \leq 1 . q$ is commonly defined as the cumulative normal distribution of mean $\mu$ and standard deviation $\sigma$ (Ogata and Katsura, 1993, 2006 and Iwata, 2008), where

$$
q(m \mid \mu, \sigma)=\int_{-\propto}^{m} \frac{1}{\sqrt{2 \pi} \sigma} e^{\frac{-(x-\mu)^{2}}{2 \sigma^{2}} d x}
$$

Equation 6, (using Eqs. 7-8) provides a model to fit the FMD over the entire magnitude range where the magnitude completeness is only implicit with

$$
M_{c}(n)=\mu+n \sigma
$$

where $n$ indicates the confidence level. $n=0$, means that $50 \%$ of the events are detected 
Syed Mustafizur Rahman, et al./Vietnam Journal of Earth Sciences 40 (2018)

above $M_{c}$, similarly $n=(1,2,3)$ means that $68 \%, 95 \%$ and $99 \%$ of the events are detected respectively. The parameters $\theta=(\beta, \mu, \sigma)$ are simultaneously obtained by maximizing the log-likelihood function

$$
\log L(\theta)=\sum_{i} \log f\left(m_{i} \mid \theta\right)
$$

with the normalized density function $f(m \mid \theta)=c \lambda(m \mid \theta), c$ being a normalization factor.

The model becomes as following (Ogata and Katsura, 2006):

$f(m \mid \beta, \mu, \sigma)=\beta e^{\left(-\beta(m-\mu)-\beta^{2 \frac{\sigma^{2}}{2}}\right)} q(m \mid \mu, \sigma)(10)$

\section{Seismic Status Estimation}

Spatial variation of seismicity parameters $M_{c}$ and $b$-value of the study area has been estimated using the Eqs.1-10. In order to observe variations of the parameters, the study area was divided into twelve uniform horizontal and twelve uniform vertical rectangular regions as shown in Figure 3 to assess seismicity parameters for each rectangular regions. It is believed that the average value would reflect the seismic status of the common region as shown (C. cell) in Figure 3 for the pair of horizontal and vertical rectangular regions.

\begin{tabular}{|c|c|c|c|c|c|c|c|c|c|c|c|c|c|}
\hline $\begin{array}{l}\text { Lat }^{\circ} \mathrm{N} / \\
\text { Long }^{\circ} \mathrm{E}\end{array}$ & $84-85$ & $85-86$ & $86-87$ & $87-88$ & $88-89$ & $89-90$ & $90-91$ & $91-92$ & $92-93$ & $93-94$ & $94-95$ & $95-96$ & \\
\hline $18-19$ & & & & C. cell & & \multicolumn{2}{|c|}{ Horizonta } & rectang & gle & & & & $\mathrm{H} 1$ \\
\hline $19-20$ & & & & & & & & & & & & & $\mathrm{H} 2$ \\
\hline $20-21$ & & & & - & & & & & & & & & $\mathrm{H} 3$ \\
\hline $21-22$ & & & & مמם & & & & & & & & & $\mathrm{H} 4$ \\
\hline $22-23$ & & & & $\frac{\pi}{\pi}$ & & & & & & & & & $\mathrm{H} 5$ \\
\hline $23-24$ & & & & U & & & & & & & & & $\mathrm{H} 6$ \\
\hline $24-25$ & & & & L & & & & & & & & & $\mathrm{H7}$ \\
\hline $25-26$ & & & & $\overline{0}$ & & & & & & & & & $\mathrm{H} 8$ \\
\hline $26-27$ & & & & एँ & & & & & & & & & $\mathrm{H} 9$ \\
\hline $27-28$ & & & & $\sum^{9}$ & & & & & & & & & $\mathrm{H} 10$ \\
\hline $28-29$ & & & & & & & & & & & & & $\mathrm{H} 11$ \\
\hline $29-30$ & & & & & & & & & & & & & $\mathrm{H} 12$ \\
\hline & V1 & V2 & V3 & V4 & V5 & V6 & V7 & V8 & V9 & V10 & V11 & V12 & \\
\hline
\end{tabular}

H-Horizontal rectangle, $\mathrm{V}$-Vertical rectangle

Figure 3. Schematic diagram of 12 horizontal (H1-12) and 12 vertical (V1-12) rectangular regions and common region as common cell for vertical and horizontal rectangular pair for the assessment of seismicity parameters

\subsection{Estimation of Seismicity in Bangladesh}

Figure 4 shows the frequency magnitude distribution (FMD), cumulative frequency distribution (CFD) and linear fitting of G-R law of earthquake events retrieved from USGS as shown in Figure 1 for the whole study area. The $b$-value and $a$-value are being obtained as 0.84 and 6.54 respectively from the analysis. This is the primary and overall estimation of the study area. As mentioned earlier that $M_{c}$ means a great deal for proper estimation of $b$ value.

In order to study a reliable estimation of $M_{c}$ four techniques as mentioned earlier in Eqs. 2-10 are applied to present catalog and the results of $M_{c}$ estimation, are shown in Table 1 and in Figures 5(a-d).
Estimated magnitude of completeness $M_{c}$ as shown in Figure 5 is varying from 3.8-4.4 (Table 1). Catalog used does not contain low or very low magnitude events. Rather it contains the events of the study area greater than magnitude 3.1. If the highest $M_{c}$ is being considered for further analysis the number of total events significantly decreased. On other hand $M_{c}$ estimations using all the techniques are seemed to be around 4.0. Since spatial variation of seismic status of the study is one of the impetuous behind the work, this work has been intended to keep the $M_{c}$ as low as possible. As a result the maximum number of events can be involved in the estimation of seismicity. In this line MAXC technique is appeared to be the right choice in this analysis. Hence, using $M_{c}=3.9$ obtained through MAXC the FMD, CMD and linear G-R 
Vietnam Journal of Earth Sciences, 40(2), 178-192

fitting over CMD once again have been estimated for the whole study area and shown in Figure 6. Estimated $b$ - and $a$-values are of 0.93

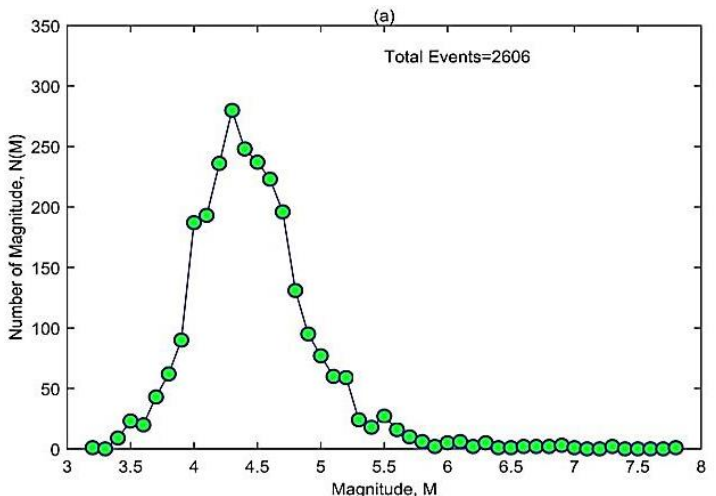

and 7.1 respectively, where $b$-value is found to be close to 1.00 which reiterates the area as seismically active zone.

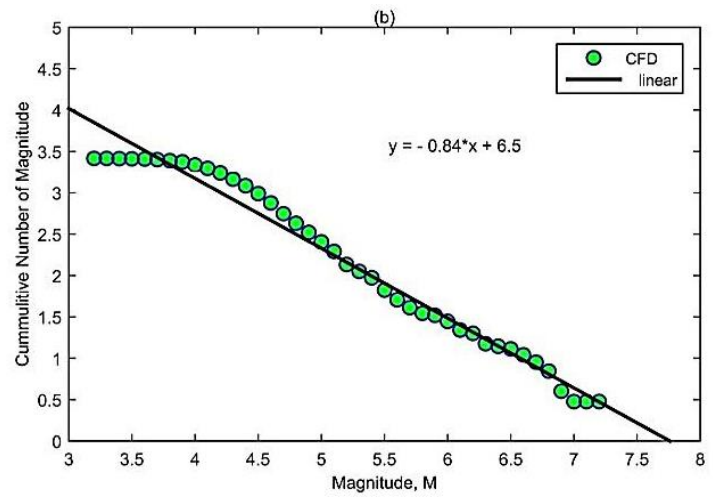

Figure 4. Earthquake magnitude distribution of the study area a) FMD and b) CFD and linear fitting of G-R law

Table 1. Estimated magnitude of completeness using different techniques

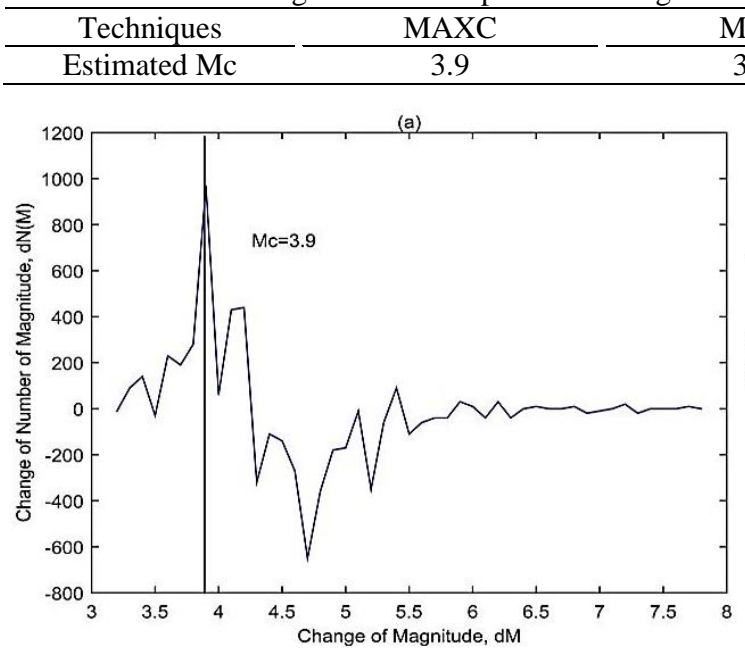
3.8
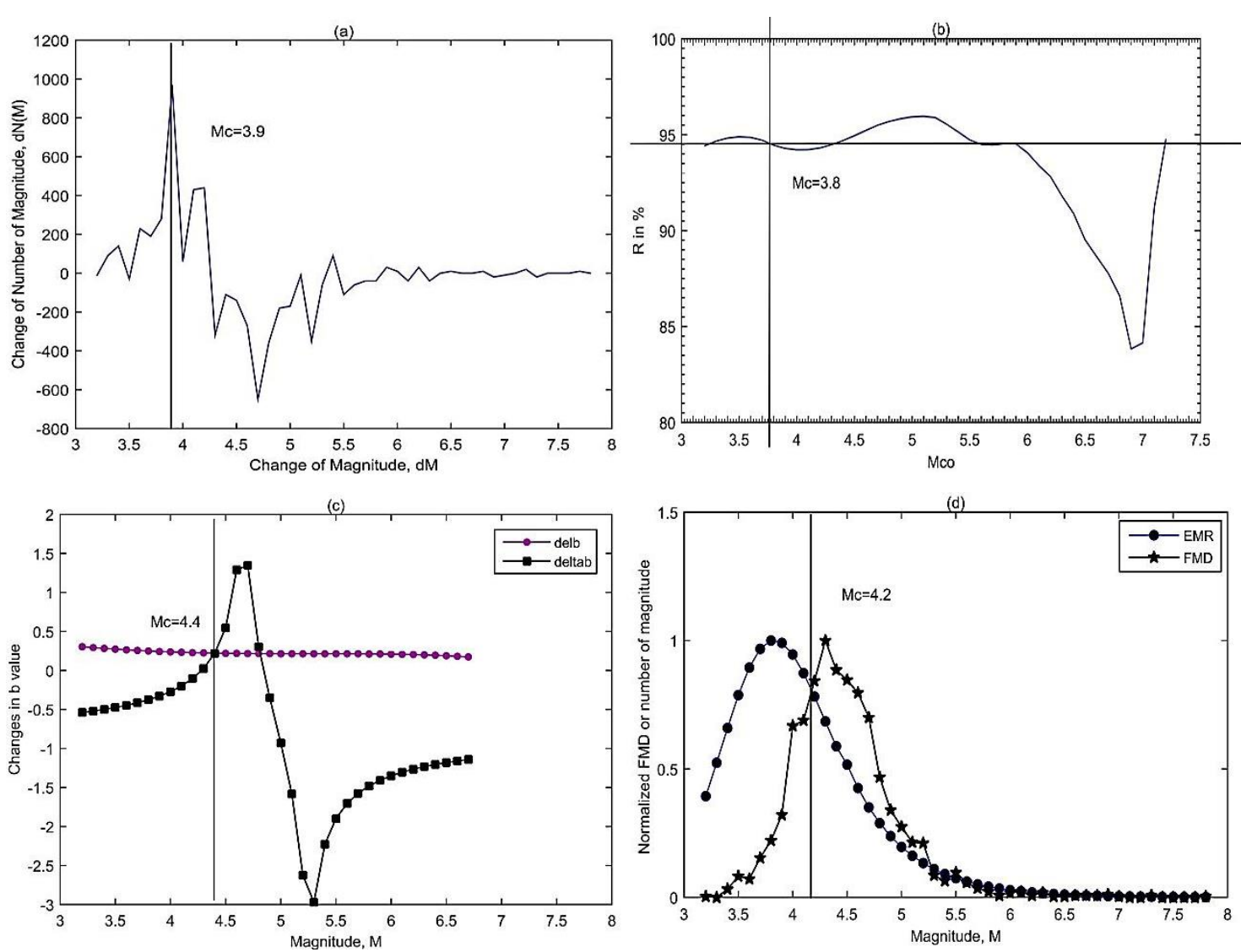

Figure 5. Estimated magnitude of completeness $M_{c}$ using a) MAXC, b) GFT, c) MBS and d) EMR techniques 

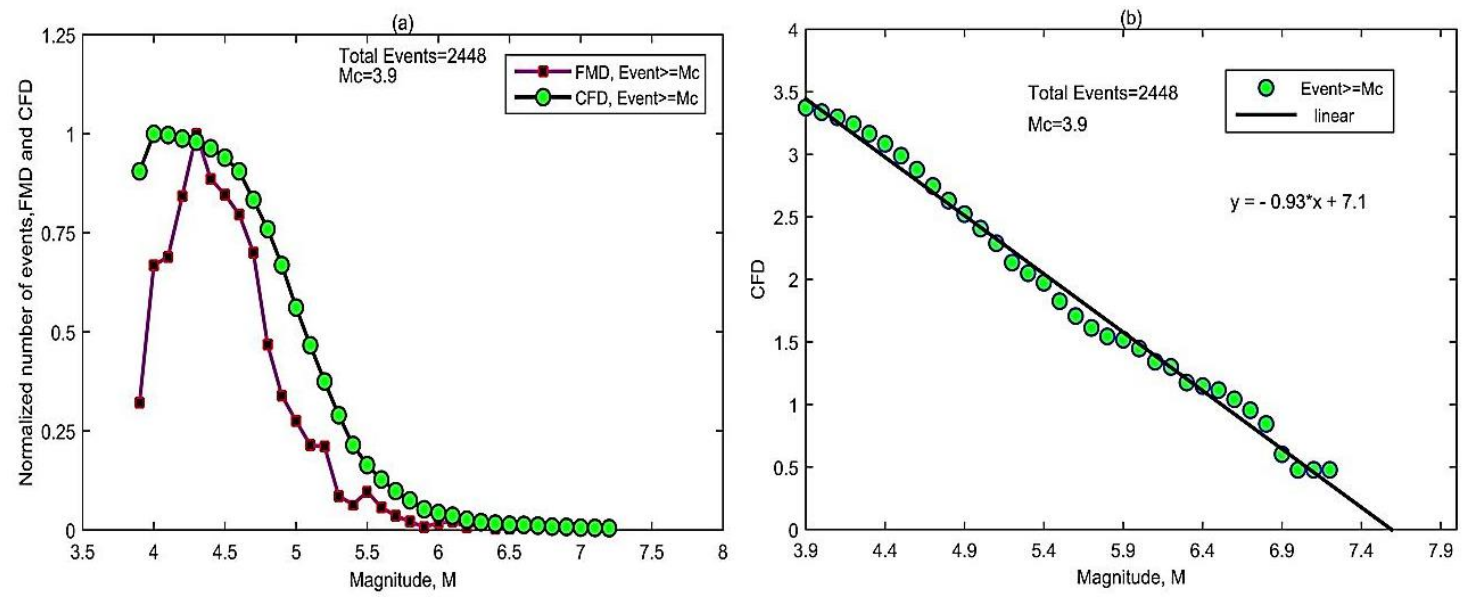

Figure 6. Estimation of $b$-value for Bangladesh using $M_{c}=3.9$. a) normalized frequency magnitude and cumulative frequency distributions, b) linear fitting of G-R law

\subsection{Spatial Variation of Seismicity in Bang- ladesh}

In order to observe spatially distributed $M_{c}$ and $b$-value the study area has divided into eleven horizontal and five vertical rectangular regions as explained in Figure 3. Objective behind the consideration of horizontal and vertical rectangles is to cover most seismicity effect from all directions. Seismicity estimations apparently may mislead as to be estimated for horizontal and vertical cells, however, seismicity parameters are to be derived for common regions of the pair of horizontal and vertical rectangles over the study area. In addition, contour or surface map to be derived using seismicity parameters for common regions would influence the nearby regions. The scheme would have also allowed a little computational advantage.

Separating data according to rectangular regions from the main earthquake catalog magnitude of completeness $M_{c} \mathrm{~s}$ are computed and shown in Table 2. Using computed $M_{C} \mathrm{~s}$ for the horizontal and vertical rectangular regions, $b$-value and $a$-value are also estimated as shown in Table 2. Later the average for the common regions of the pair of horizontal and vertical rectangles, $M_{c}$, a-value and $b$-value are being estimated and shown in Table 3.

Table 2. Estimated seismicity parameters $M_{c}, a$-value and $b$-value for the horizontal (a) and rectangular (b) regions

\begin{tabular}{|c|c|c|c|c|c|}
\hline \multicolumn{7}{|c|}{ Horizontal rectangular regions } \\
\hline Lat ${ }^{\mathrm{o}} \mathrm{N}$ & Long ${ }^{\mathrm{o}} \mathrm{E}$ & $\begin{array}{c}\text { N. of } \\
\text { Events }\end{array}$ & Mc & b-value & a-value \\
\hline 18 & $85-95$ & 40 & 4.2 & 0.90 & 5.2 \\
\hline 19 & $85-95$ & 95 & 4.5 & 0.98 & 6.0 \\
\hline 20 & $85-95$ & 71 & 4.2 & 0.77 & 4.8 \\
\hline 21 & $85-95$ & 131 & 3.9 & 0.91 & 5.8 \\
\hline 21 & $85-95$ & 131 & 3.9 & 0.91 & 5.8 \\
\hline 22 & $85-95$ & 261 & 4.1 & 1.10 & 7.1 \\
\hline 23 & $85-95$ & 322 & 3.9 & 0.97 & 6.3 \\
\hline 24 & $85-95$ & 338 & 3.9 & 0.86 & 6.0 \\
\hline 25 & $85-95$ & 187 & 3.9 & 0.93 & 5.9 \\
\hline 26 & $85-95$ & 205 & 4.1 & 1.20 & 7.1 \\
\hline 27 & $85-95$ & 502 & 3.9 & 0.92 & 6.3 \\
\hline 28 & $85-95$ & 215 & 3.9 & 0.77 & 5.2 \\
\hline 29 & $85-95$ & 240 & 4.0 & 1.10 & 6.8 \\
\hline
\end{tabular}

\begin{tabular}{|c|c|c|c|c|c|}
\hline \multicolumn{7}{|c|}{ Vertical rectangular regions } \\
\hline Lat ${ }^{\circ} \mathrm{N}$ & Long $^{\mathrm{o}} \mathrm{E}$ & $\begin{array}{c}\text { N. of } \\
\text { Events }\end{array}$ & Mc & b-value & a-value \\
\hline $18-29$ & 84 & 85 & 4.0 & 0.58 & 3.8 \\
\hline $18-29$ & 85 & 219 & 3.9 & 1.40 & 8.0 \\
\hline $18-29$ & 86 & 163 & 3.9 & 0.70 & 4.8 \\
\hline $18-29$ & 87 & 130 & 3.9 & 1.10 & 6.6 \\
\hline $18-29$ & 87 & 130 & 3.9 & 1.10 & 6.6 \\
\hline $18-29$ & 88 & 88 & 3.9 & 0.86 & 5.3 \\
\hline $18-29$ & 89 & 45 & 4.6 & 0.67 & 4.0 \\
\hline $18-29$ & 90 & 131 & 4.1 & 1.20 & 7.0 \\
\hline $18-29$ & 91 & 132 & 4.8 & 1.20 & 7.3 \\
\hline $18-29$ & 92 & 255 & 4.0 & 1.10 & 6.8 \\
\hline $18-29$ & 93 & 268 & 4.2 & 1.30 & 7.7 \\
\hline $18-29$ & 94 & 667 & 3.9 & 1.10 & 7.1 \\
\hline $18-29$ & 95 & 423 & 4.2 & 0.83 & 5.9 \\
\hline
\end{tabular}


Syed Mustafizur Rahman, et al./Vietnam Journal of Earth Sciences 40 (2018)

Table 3. Spatial distribution of seismicity parameters, varying with latitude (19-30) ${ }^{\circ} \mathrm{N}$ and longitude (85-96) ${ }^{\circ} \mathrm{E}$

\begin{tabular}{|c|c|c|c|c|c|c|c|c|c|}
\hline Lat ${ }^{\circ} \mathrm{N}$ & Long ${ }^{\circ} \mathrm{E}$ & $\mathrm{Mc}$ & $\mathrm{b}$-value & a-value & 22.50 & 87.50 & 4.00 & 1.10 & 6.85 \\
\hline 18.50 & 84.50 & 4.10 & 0.74 & 4.50 & 22.50 & 88.50 & 4.00 & 0.98 & 6.20 \\
\hline 18.50 & 85.50 & 4.05 & 1.15 & 6.60 & 22.50 & 89.50 & 4.35 & 0.89 & 5.55 \\
\hline 18.50 & 86.50 & 4.05 & 0.80 & 5.00 & 22.50 & 90.50 & 4.10 & 1.15 & 7.05 \\
\hline 18.50 & 87.50 & 4.05 & 1.00 & 5.90 & 22.50 & 91.50 & 4.45 & 1.15 & 7.20 \\
\hline 18.50 & 88.50 & 4.05 & 0.88 & 5.25 & 22.50 & 92.50 & 4.05 & 1.10 & 6.95 \\
\hline 18.50 & 89.50 & 4.40 & 0.79 & 4.60 & 22.50 & 93.50 & 4.15 & 1.20 & 7.40 \\
\hline 18.50 & 90.50 & 4.15 & 1.05 & 6.10 & 22.50 & 94.50 & 4.00 & 1.10 & 7.10 \\
\hline 18.50 & 91.50 & 4.50 & 1.05 & 6.25 & 22.50 & 95.50 & 4.15 & 0.97 & 6.50 \\
\hline 18.50 & 92.50 & 4.10 & 1.00 & 6.00 & 23.50 & 84.50 & 3.95 & 0.78 & 5.05 \\
\hline 18.50 & 93.50 & 4.20 & 1.10 & 6.45 & 23.50 & 85.50 & 3.90 & 1.19 & 7.15 \\
\hline 18.50 & 94.50 & 4.05 & 1.00 & 6.15 & Lat ${ }^{\circ} \mathrm{N}$ & Long ${ }^{\circ} \mathrm{E}$ & $\mathrm{Mc}$ & b-value & a-value \\
\hline 18.50 & 95.50 & 4.20 & 0.87 & 5.55 & 23.50 & 86.50 & 3.90 & 0.84 & 5.55 \\
\hline 19.50 & 84.50 & 4.25 & 0.78 & 4.90 & 23.50 & 87.50 & 3.90 & 1.04 & 6.45 \\
\hline 19.50 & 85.50 & 4.20 & 1.19 & 7.00 & 23.50 & 88.50 & 3.90 & 0.92 & 5.80 \\
\hline 19.50 & 86.50 & 4.20 & 0.84 & 5.40 & 23.50 & 89.50 & 4.25 & 0.82 & 5.15 \\
\hline 19.50 & 87.50 & 4.20 & 1.04 & 6.30 & 23.50 & 90.50 & 4.00 & 1.09 & 6.65 \\
\hline 19.50 & 88.50 & 4.20 & 0.92 & 5.65 & 23.50 & 91.50 & 4.35 & 1.09 & 6.80 \\
\hline 19.50 & 89.50 & 4.55 & 0.83 & 5.00 & 23.50 & 92.50 & 3.95 & 1.04 & 6.55 \\
\hline 19.50 & 90.50 & 4.30 & 1.09 & 6.50 & 23.50 & 93.50 & 4.05 & 1.14 & 7.00 \\
\hline 19.50 & 91.50 & 4.65 & 1.09 & 6.65 & 23.50 & 94.50 & 3.90 & 1.04 & 6.70 \\
\hline 19.50 & 92.50 & 4.25 & 1.04 & 6.40 & 23.50 & 95.50 & 4.05 & 0.90 & 6.10 \\
\hline 19.50 & 93.50 & 4.35 & 1.14 & 6.85 & 24.50 & 84.50 & 3.95 & 0.72 & 4.90 \\
\hline 19.50 & 94.50 & 4.20 & 1.04 & 6.55 & 24.50 & 85.50 & 3.90 & 1.13 & 7.00 \\
\hline 19.50 & 95.50 & 4.35 & 0.91 & 5.95 & 24.50 & 86.50 & 3.90 & 0.78 & 5.40 \\
\hline 20.50 & 84.50 & 4.10 & 0.68 & 4.30 & 24.50 & 87.50 & 3.90 & 0.98 & 6.30 \\
\hline 20.50 & 85.50 & 4.05 & 1.09 & 6.40 & 24.50 & 88.50 & 3.90 & 0.86 & 5.65 \\
\hline 20.50 & 86.50 & 4.05 & 0.74 & 4.80 & 24.50 & 89.50 & 4.25 & 0.77 & 5.00 \\
\hline 20.50 & 87.50 & 4.05 & 0.94 & 5.70 & 24.50 & 90.50 & 4.00 & 1.03 & 6.50 \\
\hline 20.50 & 88.50 & 4.05 & 0.82 & 5.05 & 24.50 & 91.50 & 4.35 & 1.03 & 6.65 \\
\hline 20.50 & 89.50 & 4.40 & 0.72 & 4.40 & 24.50 & 92.50 & 3.95 & 0.98 & 6.40 \\
\hline 20.50 & 90.50 & 4.15 & 0.99 & 5.90 & 24.50 & 93.50 & 4.05 & 1.08 & 6.85 \\
\hline Lat ${ }^{\circ} \mathrm{N}$ & Long ${ }^{\circ} \mathrm{E}$ & $\mathrm{Mc}$ & b-value & a-value & 24.50 & 94.50 & 3.90 & 0.98 & 6.55 \\
\hline 20.50 & 91.50 & 4.50 & 0.99 & 6.05 & 24.50 & 95.50 & 4.05 & 0.85 & 5.95 \\
\hline 20.50 & 92.50 & 4.10 & 0.94 & 5.80 & 25.50 & 84.50 & 3.95 & 0.76 & 4.85 \\
\hline 20.50 & 93.50 & 4.20 & 1.04 & 6.25 & 25.50 & 85.50 & 3.90 & 1.17 & 6.95 \\
\hline 20.50 & 94.50 & 4.05 & 0.94 & 5.95 & 25.50 & 86.50 & 3.90 & 0.82 & 5.35 \\
\hline 20.50 & 95.50 & 4.20 & 0.80 & 5.35 & 25.50 & 87.50 & 3.90 & 1.02 & 6.25 \\
\hline 21.50 & 84.50 & 3.95 & 0.75 & 4.80 & 25.50 & 88.50 & 3.90 & 0.90 & 5.60 \\
\hline 21.50 & 85.50 & 3.90 & 1.16 & 6.90 & 25.50 & 89.50 & 4.25 & 0.80 & 4.95 \\
\hline 21.50 & 86.50 & 3.90 & 0.81 & 5.30 & 25.50 & 90.50 & 4.00 & 1.07 & 6.45 \\
\hline 21.50 & 87.50 & 3.90 & 1.01 & 6.20 & 25.50 & 91.50 & 4.35 & 1.07 & 6.60 \\
\hline 21.50 & 88.50 & 3.90 & 0.89 & 5.55 & 25.50 & 92.50 & 3.95 & 1.02 & 6.35 \\
\hline 21.50 & 89.50 & 4.25 & 0.79 & 4.90 & 25.50 & 93.50 & 4.05 & 1.12 & 6.80 \\
\hline 21.50 & 90.50 & 4.00 & 1.06 & 6.40 & 25.50 & 94.50 & 3.90 & 1.02 & 6.50 \\
\hline 21.50 & 91.50 & 4.35 & 1.06 & 6.55 & 25.50 & 95.50 & 4.05 & 0.88 & 5.90 \\
\hline 21.50 & 92.50 & 3.95 & 1.01 & 6.30 & 26.50 & 84.50 & 4.05 & 0.89 & 5.45 \\
\hline 21.50 & 93.50 & 4.05 & 1.11 & 6.75 & 26.50 & 85.50 & 4.00 & 1.30 & 7.55 \\
\hline 21.50 & 94.50 & 3.90 & 1.01 & 6.45 & 26.50 & 86.50 & 4.00 & 0.95 & 5.95 \\
\hline 21.50 & 95.50 & 4.05 & 0.87 & 5.85 & 26.50 & 87.50 & 4.00 & 1.15 & 6.85 \\
\hline 22.50 & 84.50 & 4.05 & 0.84 & 5.45 & 26.50 & 88.50 & 4.00 & 1.03 & 6.20 \\
\hline 22.50 & 85.50 & 4.00 & 1.25 & 7.55 & 26.50 & 89.50 & 4.35 & 0.94 & 5.55 \\
\hline 22.50 & 86.50 & 4.00 & 0.90 & 5.95 & 26.50 & 90.50 & 4.10 & 1.20 & 7.05 \\
\hline
\end{tabular}


Syed Mustafizur Rahman, et al./Vietnam Journal of Earth Sciences 40 (2018)

\begin{tabular}{|c|c|c|c|c|}
\hline 26.50 & 91.50 & 4.45 & 1.20 & 7.20 \\
\hline Lat $^{\circ} \mathrm{N}$ & Long $^{\circ} \mathrm{E}$ & $\mathrm{Mc}$ & b-value & a-value \\
\hline 26.50 & 92.50 & 4.05 & 1.15 & 6.95 \\
\hline 26.50 & 93.50 & 4.15 & 1.25 & 7.40 \\
\hline 26.50 & 94.50 & 4.00 & 1.15 & 7.10 \\
\hline 26.50 & 95.50 & 4.15 & 1.02 & 6.50 \\
\hline 27.50 & 84.50 & 3.95 & 0.75 & 5.05 \\
\hline 27.50 & 85.50 & 3.90 & 1.16 & 7.15 \\
\hline 27.50 & 86.50 & 3.90 & 0.81 & 5.55 \\
\hline 27.50 & 87.50 & 3.90 & 1.01 & 6.45 \\
\hline 27.50 & 88.50 & 3.90 & 0.89 & 5.80 \\
\hline 27.50 & 89.50 & 4.25 & 0.80 & 5.15 \\
\hline 27.50 & 90.50 & 4.00 & 1.06 & 6.65 \\
\hline 27.50 & 91.50 & 4.35 & 1.06 & 6.80 \\
\hline 27.50 & 92.50 & 3.95 & 1.01 & 6.55 \\
\hline 27.50 & 93.50 & 4.05 & 1.11 & 7.00 \\
\hline 27.50 & 94.50 & 3.90 & 1.01 & 6.70 \\
\hline 27.50 & 95.50 & 4.05 & 0.88 & 6.10 \\
\hline 28.50 & 84.50 & 3.95 & 0.68 & 4.50 \\
\hline 28.50 & 85.50 & 3.90 & 1.09 & 6.60 \\
\hline 28.50 & 86.50 & 3.90 & 0.74 & 5.00 \\
\hline
\end{tabular}

\begin{tabular}{|l|l|l|l|l|}
\hline 28.50 & 87.50 & 3.90 & 0.94 & 5.90 \\
\hline 28.50 & 88.50 & 3.90 & 0.82 & 5.25 \\
\hline 28.50 & 89.50 & 4.25 & 0.72 & 4.60 \\
\hline 28.50 & 90.50 & 4.00 & 0.99 & 6.10 \\
\hline 28.50 & 91.50 & 4.35 & 0.99 & 6.25 \\
\hline 28.50 & 92.50 & 3.95 & 0.94 & 6.00 \\
\hline 28.50 & 93.50 & 4.05 & 1.04 & 6.45 \\
\hline 28.50 & 94.50 & 3.90 & 0.94 & 6.15 \\
\hline 28.50 & 95.50 & 4.05 & 0.80 & 5.55 \\
\hline 29.50 & 84.50 & 4.00 & 0.84 & 5.30 \\
\hline 29.50 & 85.50 & 3.95 & 1.25 & 7.40 \\
\hline 29.50 & 86.50 & 3.95 & 0.90 & 5.80 \\
\hline 29.50 & 87.50 & 3.95 & 1.10 & 6.70 \\
\hline 29.50 & 88.50 & 3.95 & 0.98 & 6.05 \\
\hline 29.50 & 89.50 & 4.30 & 0.89 & 5.40 \\
\hline 29.50 & 90.50 & 4.05 & 1.15 & 6.90 \\
\hline 29.50 & 91.50 & 4.40 & 1.15 & 7.05 \\
\hline 29.50 & 92.50 & 4.00 & 1.10 & 6.80 \\
\hline 29.50 & 93.50 & 4.10 & 1.20 & 7.25 \\
\hline 29.50 & 94.50 & 3.95 & 1.10 & 6.95 \\
\hline 29.50 & 95.50 & 4.10 & 0.97 & 6.35 \\
\hline
\end{tabular}

\subsection{Seismic Status Map of Bangladesh}

Table 2 and 3 show the seismicity parameters at different locations in Bangladesh, particularly at 144 regions, the common area of

vertical and horizontal pair rectangular regions. Using these parameters, $M_{c}, a$ - and $b$-values as shown in Table 3 contour maps along with the surface maps for Bangladesh polygon are being derived and shown in Figures 7-9.

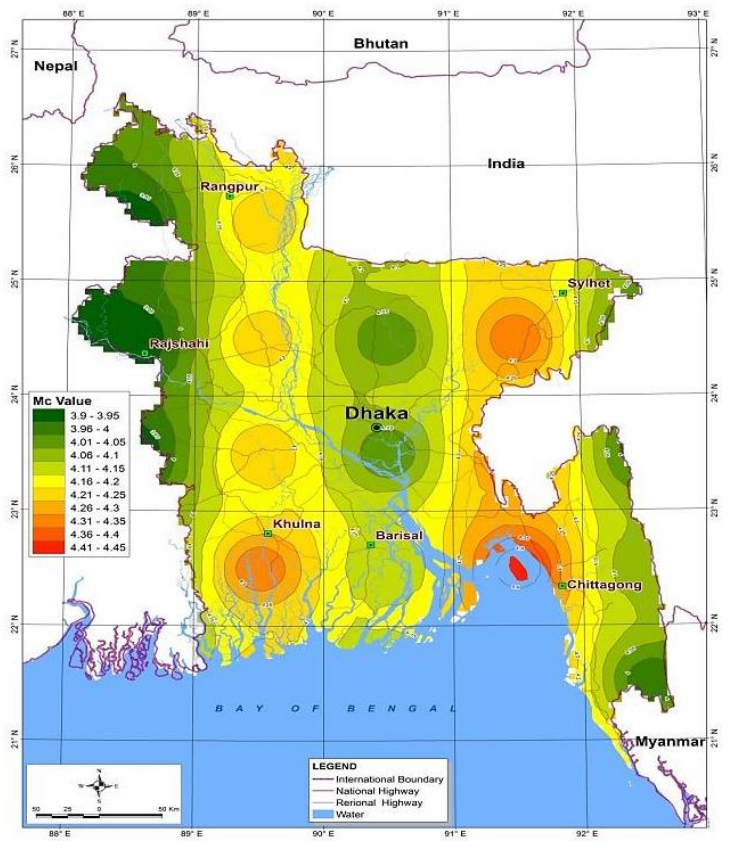

Figure 7. Spatially distributed magnitude of completeness in Bangladesh

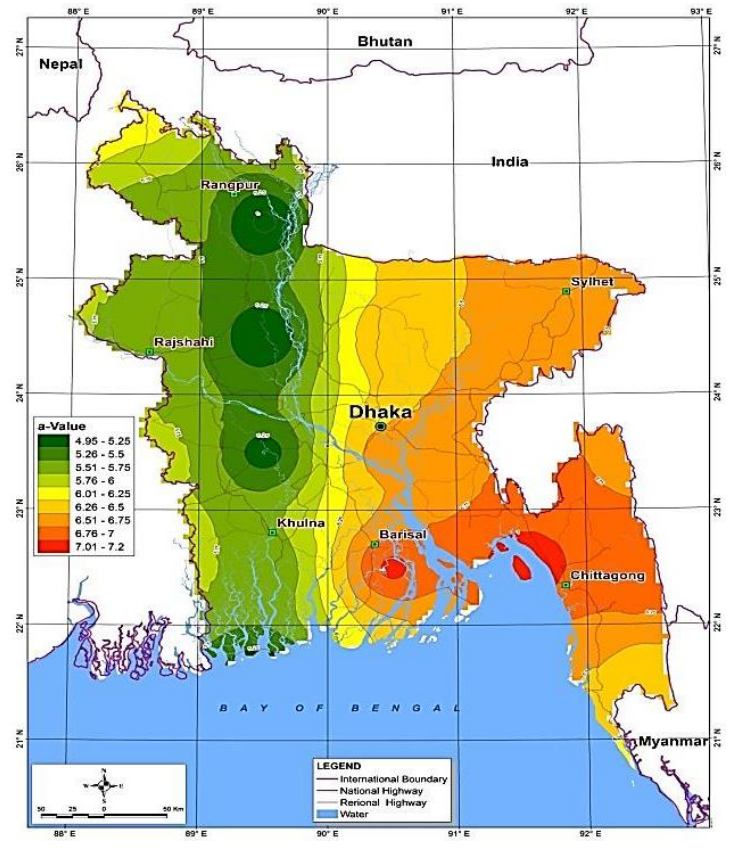

Figure 8. Spatially distributed $a$-value in Bangladesh 
Syed Mustafizur Rahman, et al./Vietnam Journal of Earth Sciences 40 (2018)

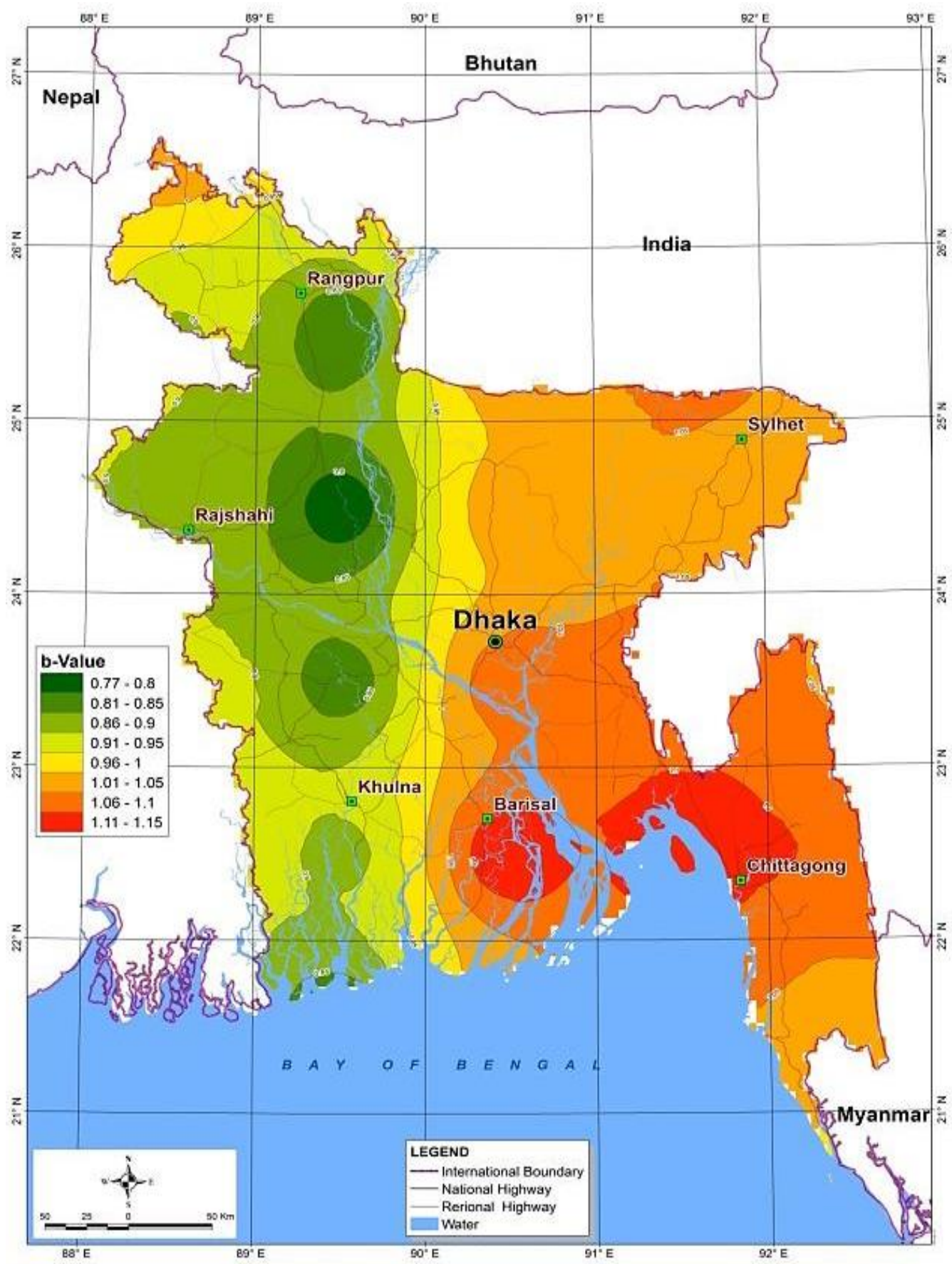

Figure 9. Spatially distributed $b$-value in Bangladesh

Estimated magnitude completeness $M_{c}$ using maximum curvature technique is of 3.9 and using MBS is 3.8 as shown in Figure 5(a- b). However, using two other methods as mentioned through the Eqs. 3-6, $M_{c}$ estimations were observed little high or greater than 
Syed Mustafizur Rahman, et al./Vietnam Journal of Earth Sciences 40 (2018)

4.0. It has observed from the earthquake cata$\log$ that if higher values are being set to $M_{c}$, it is evident that the significant number of earthquake events were to be found beyond threshold level. Magnitudes of earthquake events less than 3.0 were not available in the catalog. Hence, in order to increase the participation of maximum number of events in the analysis, MAXC technique is appeared to be better one and used to estimate the $M_{c}$. Estimated $M_{c}$ s are varying from 3.8-4.4, which are seemed to be well estimated. Recent contributions have shown the almost similar estimation of magnitude completeness of the area. Das et al. (2012) have estimated the value of $M_{c}$ for N-E India in the zone VII and VIII as 3.9 and 3.7 respectively.

The zones VII and VIII are basically the northern and southern parts of Bangladesh. Kolathayar et al. (2012) have shown that $M_{c}$ is varying from 4.25-4.5 for Bangladesh region along with India and adjoining area. While Khan et al. (2011) have approximated $M_{c}$ value around 3.0 for N-E India. From all above analyses including the present analyses it can be said that the magnitude completeness of the study area is close to 4.0. This work has suggested the same results of magnitude completeness as obtained and shown in Figure 5(a-d) as varying from 3.8-4.2 using various techniques. It is also notable that Das et al. (2012) have shown $M_{c}=3.9$ in zone VII using four catalogs that include historical seismicity catalog as well and it was difficult to convert to a uniform magnitude scale, while the present analysis for the same area has shown almost similar magnitude completeness, $M_{c}=3.9$ using MAXC technique for a single catalog. Kolathayar et al. (2012) have done the same job taking historical and instrumental data but estimated slightly higher magnitude of completeness varying 4.25-4.5 for Bangladesh region. It is essential to learn a reliable estimation of $M_{c}$ of an area though it can vary with time and space. There are limitations to inte- grate all historical and instrumental data from different sources for seismicity analysis. Addition of time, spatial variation in seismicity and heterogeneity of earth could make the work too complicated. However, it has been said in most contributions that the assessment becomes more convincing while number of events can be increased in the catalog. Present research has emphasized on increasing number of events only from one source in order to keep it bias free. Above contributions as mentioned earlier have estimated seismicity for the whole area but not shown spatial variation of $M_{c}$ for Bangladesh preciously. This work has estimated over all magnitude of completeness $M_{C}=3.9$ of the study area and defined the spatial variation of magnitude of completeness varying from 3.90-4.45 for the whole Bangladesh. Figure 7 shows a reliable magnitude completeness map, which can be employed further whenever required, with spatially distributed $M_{c}$ along with 0.05 interval contour lines. It has observed that $M_{c}$ is low at the border line of N-W Bangladesh, and a line from Cox's Bazaar to Sylhet through Hill tracts.

Khan et al. (2011) have shown $b$-values in $\mathrm{N}$-E India for zone I, where $b$-value is varying from $0.5-0.7$. This zone $\left(24.5-25.2^{\circ} \mathrm{N}\right.$ and $90-$ $92^{\circ} \mathrm{E}$ ) is partially common to the study area considered in this work. While the present analyses have presented the $b$-value varying from 0.77-1.15 in Table 3 and Figure 9, which is slightly higher. However, the variability in the seismic activity rate across the whole of India and adjoining areas has quantified in another contribution made by S. Kolathayar et al. (2012). This quantification has covered the total study area of the present analysis, where, $b$-value distributions in Bangladesh have shown as varying from $0.7-0.8$. Present analyses have estimated almost the same $b$-value as varying 0.77-1.15 as shown Figure 9 except the region the central part of Barisal and Khulna divisions, where the $b$-value is ap- 
peared to be greater than 1.1. There are few more contributions to assess the $b$-value of SE Asia including Bangladesh and in most of the contributions, the $b$-value has shown varying from 0.6-1.3 (Siddique, 2015 and AlHussaini, 2006). Hence, the $b$-value is seemed to be well estimated and quantified with an interval equal to 0.005 through spatially distributed $b$-value as shown in Figure 9. It was so far not yet visualized before the spatially varied seismicity parameters in Bangladesh. Present work has developed spatially varying magnitude of completeness $M_{c}, \quad b$-value and $a$-value in Bangladesh. The $a$-value varying form 4.95-7.20 has also presented and shown in Figure 8.

\section{Conclusions}

The work may appear to be disadvantageous as used only the USGS earthquake cata$\log$ for the analysis. But it is advantageous because the events are being recorded, transmitted or processed uniformly by one organization and catalog is biased by processing or transmitting mechanisms only from one organization. If other catalogs were to be integrated there would be different mechanisms to be used. Even different type of recording instruments can cause further problems along with instrumental drifts. In such cases, the work may appear to be complicated to convert into a unique scale. The number of events in the catalog may be another issue but a total of 2606 events and magnitudes from 3.0-8.0 can be accounted as reasonable for seismicity analysis. Indeed integration of other catalogs and conversions into unique scale could produce the better analysis.

Earthquake events and caused damages are not seemed to be uniform to all directions from the source. Apparently, earthquake distributions vary from place to place. It depends mostly upon the geologic condition of an area as sediments and geologic structure varies from one area to another. Findings of this work were basically primitive measures of seismicity for uniform long horizontal and vertical areas. Later the results are being integrated for common area, and to present the estimations in the form of maps. Spatially distributed seismicity parameters as $a$-value, $b$ value and $M_{c}$ distributions of the country have been estimated and presented in maps. These maps might be valuable aid for engineering constructions and seismic hazard estimation. Estimated $b$-value obtained $b>1.0$ is being indicated a significant proportion of small earthquakes to the large one for the whole NE Bangladesh, where central part of Barisal and Chittagong divisions including the port city Chittagong is being visualized as the highest state of $b$-value $(b=1.15)$ in the country.

It would be far better for $a$-value, $b$-value and $M_{c}$ distributions in the country if the cata$\log$ could contain small or very small magnitude earthquake events. Neither local magnitude distributions recorded at seismic stations in Bangladesh were available, nor were the seismic networks found to be dense enough. On the contrary, small events are not the threats for damages. Within the limitations, this research work was intended to produce reliable $a$-value, $b$-value, and $M_{c}$ distributions. In this context, the work has contemplated and employed different techniques to obtain the magnitude of completeness, $M_{c}$. An overall $a=7.1$, $b=0.93$ and $M_{c}=3.9$ values of seismicity parameters estimation in S-E Asia and Bangladesh indicate that the area is of a highly active seismic zone. Spatially distributed $M_{c}$ and $b$ value in Bangladesh presented in this work might be a useful aid for further development of seismological activities in the area.

\section{Acknowledgements}

Authors acknowledge Earthquake Hazards Program of USGS for making downloadable earthquake data available in their site. 


\section{References}

Abercrombie R.E., and Brune J.N., 1994. Evidence for a constant b-value above magnitude 0 in the southern San Andreas, San Jacinto, and San Miguel fault zones and at the Long Valley caldera, California. Geophys. Res. Lett., 21(15), 1647-1650.

Aki K., 1965. Maximum likelihood estimate of $b$ in the formula $\log \mathrm{N}=\mathrm{a}-\mathrm{b} \mathrm{M}$ and its confidence limits. Bull. Earthquake Res Inst., Tokyo Univ., 43, 237-239.

Aki S., 1987. On nonparametric tests for symmetry. Ann. Inst. Statist. Math., 39, 457-472.

Al-Hussaini T.M., 2006. Seismicity and Seismic Hazard Assessment in Bangladesh: Reference to Code Provisions. Meeting on Seismic Hazard in Asia ICTP, Trieste, Dec. 4-8.

Amorese D., 2007. Applying a change-point detection method on frequency-magnitude distributions. Bull. Seismol. Soc. Am., 97(5), 1742-1749. Doi:10.1785/0120060181.

Banglapedia, 2012. The National Encyclopedia of Bangladesh.

http://en.banglapedia.org/index.php?title=Tectonic Framework, retrieved on 31 Aug 2017.

Cao A.M., and Gao S.S., 2002. Temporal variations of seismic b-values beneath northeastern Japan island arc. Geophys. Res. Lett., 29(9), 481-483. Doi:10.1029/2001GL013775.

Das R., Wason H.R., and Sharma M.L., 2012. Temporal and spatial variations in the magnitude of completeness for homogenized moment magnitude catalogue for northeast India. J. Earth Syst. Sci., 121(1), 19-28.

Felzer K.R., 2008. Simulated aftershock sequences for a M 7.8 earthquake on the southern San Andreas fault. Seismol. Res. Lett., 80, 21-25.

GSB, 2018. Seismic Zone Map of Bangladesh. http://gsb.portal.gov.bd/sites/default/files/files/gsb.p ortal.gov.bd/common_document/a6e75ad2_5acd_4f e3_911d_c9d25a7e349e/BD_Sciesmiczonemap(NBC).pdf, retrieved on 31 March 2018.

Gutenberg B., and Richter C.F., 1944. Frequency of earthquakes in California, Bull. Seismol. Soc. Am., 34, 184-188.

Gutenberg B., and Richter C.F., 1956. Earthquake magnitude, intensity, energy and acceleration (second paper). Bull. Seismol Soc. Am., 46(2), 105-145.
Hafiez H.E.A., 2015. Estimating the magnitude of completeness for assessing the quality of earthquake catalogue of the ENSN. Egypt. Arab J. Geosci., 8(1), 9315-9323. Doi:10.1007/s12517-015-1929-x.

Hunting Geology and Geophysics Ltd., (1981), Interpretation and Operations report on an aeromagnetic survey in Bangladesh, Borehamwood, Hertfordshire, England.

Iwata T., 2008. Low detection capability of global earthquakes after the occurrence of large earthquakes: investigation of the Harvard cmt catalogue. Geophys. J. Int., 174(3), 849-856. Doi:10.1111/j.1365-246X.2008.03864.x.

Kagan Y.Y., 2002. Seismic moment distribution revisited: I. statistical results. Geophys. J. Int., 148(3), 520541. Doi: 10.1046/j.1365-246x.2002.01594.x.

Khan P.K., Ghosh M., Chakraborty P.P., and Mukherjee D., 2011. Seismic b-Value and the Assessment of Ambient Stress in Northeast India. Pure Appl. Geophys., 168(10), 1693-1706. Doi:10.1007/s00024010-0194-x.

Kolathayar S., Sitharam T.G., and Vipin K.S., 2012. Spatial variation of seismicity parameters across India and adjoining areas. Nat Hazards, 60(3), 13651379. Doi:10.1007/s11069-011-9898-1.

Lomnitz-Adler J., and Lomnitz C., 1979. A modified form of the Gutenberg-Richter magnitude-frequency relation. Bull. Seism. Soc. Am., 69(4), 1209-1214.

Marsan D., 2003. Triggering of seismicity at short timescales following Californian earthquakes. J. Geophys. Res., 108, B5, 2266. Doi:10.1029/2002JB001946.

Mignan A., 2011. Retrospective on the Accelerating Seismic Release (ASR) hypothesis: Controversy and new horizons. Tectonophysics, 505(1), 1-16. Doi:10.1016/j.tecto.2011.03.010.

Mignan A., and Woessner J., 2012. Estimating the magnitude of completeness for earthquake catalogs, Community Online Resource for Statistical Seismicity Analysis. Swiss Seismological Service, ETH Zurich, 145p. Doi:10.5078/corssa-00180805. Available at http://www.corssa.org.

Naylor M., Orfanogiannaki, K., and Harte D., 2010. Exploratory data analysis: magnitude, space, and time. Community Online Resource for Statistical Seismicity Analysis, 42p. Doi:10.5078/corssa-92330203. Available at http://www.corssa.org.

Ogata Y., and Katsura K., 1993. Analysis of temporal and spatial heterogeneity of magnitude frequency 
Vietnam Journal of Earth Sciences, 40(2), 178-192

distribution inferred from earthquake catalogues. Geophys. J. Int., 113(3), 727-738. Doi:10.1111/j.1365-246X.1993.tb04663.x.

Ogata Y., and Katsura K., 2006. Immediate and updated forecasting of aftershock hazard. Geophys. Res. Lett., 33, 10, L10305. Doi:10.1029/2006GL025888.

Rashid H., 1991. Geography of Bangladesh, University Press Ltd, Bangladesh; 2nd edition, 545p.

Reimann K.U., 1993. Geology of Bangladesh. Gerbruder Bornt Ramerg, Berlin, Germany. 160p.

Siddique S., 2015. Gutenberg-Richter recurrence law to seismicity analysis of Bangladesh. IABSE-JSCE Joint Conference on Advances in Bridge Engineering-III, August 21-22, Dhaka, Bangladesh.

Shi Y., and Bolt B.A., 1982. The standard error of the magnitude-frequency b-value. Bull. Seismol. Soc. Am., 72(5), 1667-1687.

USGS, 2012. Earthquake Hazards Program. https://earthquake.usgs.gov/earthquakes/search/, USA, retrieved on 20 April 2017.

Utsu T., 1999. Representation and analysis of the earthquake size distribution: a historical review and some new approaches. Pure Appl. Geophys., 155(2), 509-535.

Wiemer S., and Wyss M., 2000. Minimum magnitude of complete reporting in earthquake catalogs: examples from Alaska, the western United States, and Japan. Bull. Seismol. Soc. Am., 90, 859-869. Doi:10.1785/0119990114.

Woessner J., and Wiemer S., 2005. Assessing the quality of earthquake catalogues: Estimating the magnitude of completeness and its uncertainty. Bull. Seismol. Soc. Am., 95(2), 684-698. Doi:10.1785/012040007.

Wyss M., Hasegawa A., Wiemer S., and Umino N., 1999. Quantitative mapping of precursory seismic quiescence before the 1989, M7.1 off-Sanriku earthquake, Japan. Annali Di Geoflsica, 42(5), 851-869.

Zuniga F.R., and Wyss M., 1995. Inadvertent changes in magnitude reported in earthquake catalogs: Their evaluation through b-value estimates. Bull. Seismol. Soc. Am., 85, 1858-1866.

.Zuniga F.R., and Wiemer S., 1999. Seismicity patterns: Are they always related to natural causes? Pure Appl. Geophys., 155(2), 713-726. 